\begin{tabular}{l|l|l|l|l}
\hline Volume 2 & Issue 3 & December (2021) & DOI: 10.47540/ijsei.v2i3.297 & Page: $221-226$ \\
\hline
\end{tabular}

\title{
Integrating Indigenous Knowledge Systems in Entrepreneurship: A Case of Horticulture Farmers in Mutoko District of Zimbabwe
}

\author{
Shingirai S. Mugambiwa \\ Department of Social Work, University of Limpopo, South Africa \\ Corresponding Author: Shingirai S. Mugambiwa; Email: mugambiwashingirai@gmail.com
}

\begin{tabular}{|c|c|}
\hline A R T I C & E I N F O \\
\hline $\begin{array}{l}\text { Keywords } \\
\text { Horticultu } \\
\text { Sustainab }\end{array}$ & $\begin{array}{l}\text { Entrepreneurship; } \\
\text {; Mutoko District; } \\
\text { Development. }\end{array}$ \\
\hline Received & : 16 July 2021 \\
\hline Revised & : 20 December 2021 \\
\hline Accepted & : 22 December 2021 \\
\hline
\end{tabular}

A R T I C LE I N F O

Keywords: Entrepreneurship; Horticulture; Mutoko District

Received : 16 July 2021

Accepted : 22 December 2021

\begin{abstract}
A B S T R A C T
Entrepreneurship plays a significant role in eradicating poverty and providing sustainable livelihoods for communities. Governments, non-governmental organizations, and community development agencies are on the trail to consider rural entrepreneurship as an economic empowerment strategy in the developing world. Given the shortcomings of the Western entrepreneurship skills widely employed in many communities, this study assesses the role and significance of an approach that is place-based and rooted in local cultures that are associated with long-settled communities with strong ties to their natural environments. Nevertheless, a plethora of entrepreneurial strategies employed is foreign to local communities, which makes it difficult to produce the anticipated outcome vis-à-vis sustainable development. The study employs a qualitative method and an exploratory design. The findings of this research are based on in-depth interviews conducted among horticulture farmers in the Mutoko district. The significance of embracing Indigenous Knowledge Systems (IKS) in entrepreneurship among horticulture farmers in the Mutoko district was examined. Horticulture is a popular kind of farming in the region, with farmers specializing in tomatoes, cucumbers, leafy vegetables, onions, and butternut.
\end{abstract}

\section{INTRODUCTION}

Entrepreneurship is an important aspect of agriculture and farming. The success and future of farmers are determined by their entrepreneurial ability in the way they run their farms (Kuchi, Salma \& Kabir, 2017). Farmers who produce for the market and for-profits have a mandate to strategically position themselves as entrepreneurs. However, being entrepreneurial is challenging for small-scale farmers as they require assistance from other institutions. An entrepreneur is defined as someone who produces for the market with determination and creativity to identify opportunities to improve his/her business (Sidhu, \& Kaur, 2006; Kuchi, Salma \& Kabir, 2017). Entrepreneurs take calculated risks and assume responsibility for profits and losses. Entrepreneurs are passionate about business growth and they constantly look for new opportunities. Innovation is a significant quality for a farmer-entrepreneur. Entrepreneurship is not limited to large- scale/commercial farmers. All over the world, small-scale farmers have shown a remarkable ability to act like entrepreneurs. Studies around the world have established that small-scale farmers have crafted better ways to organize their farms (Mugambiwa, 2018; Chikosi et al 2018; Gandure, Walker \& Botha, 2013). It has emerged that smallscale farmers have long refrained from sticking to traditional crops for subsistence purposes. Rather, the focus has shifted to trying new crops and better animals, and alternative technologies aimed at increasing productivity, diversifying production, reducing risks, and ultimately increasing profits. In essence, small-scale farmers are becoming more market-oriented and they are learning to take calculated risks to open or create new markets for their products.

Thus far, it can be been established that innovation is fundamental in entrepreneurship, and in addition to innovation, many other essential resources are needed. In that regard, it is important 
to take into consideration the fact that smallholder farmers in communities such as Mutoko district do not have access to the aforementioned alternative technologies to support their entrepreneurial activities. This, therefore, brings about the need for Indigenous Knowledge Systems which I suppose is readily available to them. The quest for entrepreneurship among smallholder farmers is largely strengthened by their level of creativity and innovation. It has been established that to be successful, small-scale farmers entrepreneurs need to manage their businesses as long-term ventures to make them sustainable. Another important aspect is their ability to identify opportunities and seize them.

Despite having access to modern technology and other alternative components suggested earlier on, some small-scale farmers still focus on maintaining their traditional methods. This implies that their production decisions are motivated by what they need rather than what is possible. In essence, the focus of the farmer-entrepreneur will be to firmly determine what is possible and the future he/she wants bearing in mind that what is possible is determined by the market. As such new opportunities will be found in the market. Hence, this study seeks to determine the impact of embracing IKS in horticulture entrepreneurship. The need for IKS in entrepreneurship is largely supported by the fact that Indigenous knowledge is considered the social capital of the poor (Mugambiwa, 2018; Senanayake, 2006).

IKS constitutes one of their major assets in the struggle for survival and food production food. Senanayake (2006) contends that IKS equates to sustainable development due to the fact that a plethora of foreign technologies and development concepts are short-lived and they often promise short-term gains or solutions to problems without sufficient capacity to sustain them. Horticulture is a significant agro-based industry that improves the productivity of the land, generates employment, and improves the economic conditions of farmers. (Mugambiwa \& Rukema, 2019). The horticulture sector comprises fruits, vegetables, spices, and flowers to mention a few. In India, fruits and vegetables account for nearly $90 \%$ of the total horticulture products making it the second-largest producer of fruits and vegetables in the world. Horticultural crops are commonly grown on a commercial scale to provide a livelihood to farmers.
As such, the individual who organizes manages and assumes the risk of business is an entrepreneur. This study seeks to establish the role and significance of IKS in horticulture entrepreneurship among smallholder farmers in rural Zimbabwe.

\section{Materials AND MethodS}

A qualitative approach and an exploratory research design were used in this study. Exploratory research is used to find answers to questions about a research topic that has not been thoroughly investigated (Shields \& Rangarjan, 2013). The necessity for an exploratory design arises from the fact that indigenous knowledge and entrepreneurship have not been fully explored. The study's participants were all horticultural farmers in Mutoko District. Ten (10) participants were selected using purposive sampling, and data was collected through in-depth interviews. The selection of participants was inspired by the availability of small-scale farmers who produce for the market for at least ten years. As such, ten participants from three villages in the district met the criteria. Data were analyzed using thematic content analysis (TCA). According to Braun and Clarke (2006), TCA works by breaking down the material gathered into themes and then following the steps:

Phase 1: Familiarising with the data

Phase 2: Generating initial codes

Phase 3: Searching and reviewing themes

Phase 4: Searching, defining, and naming themes

Phase 5: Interpret and compile information.

Mutoko is situated in Zimbabwe's under Mashonaland East Province and it has a total area of 4,092.5 square kilometers (Mvumi et al., 1988). The district contains 146127 inhabitants according to the 2012 population census (Moyo, 2016). A growing point, community spaces, resettlement farms, and small-scale commercial farms make up the district (Bhatasara, 2016). The district is dominated by conservation farming. Natural ecological processes are exploited to retain moisture, improve soil fertility, improve soil structure, and reduce the occurrence of diseases in this farming practice. Horticulture is popular in the area, with farmers specializing in tomatoes, onions, leafy greens, butternut squash, and cucumbers. Crop production is not sustainable in most of the district due to high temperatures unless irrigation is available (Moyo, 2016). 


\section{RESULTS AND DISCUSSION \\ IKS and Entrepreneurship in horticulture}

Horticulture farmers in Mutoko district employ a variety of farming methods that fall within the confines of IKS. These methods include crop rotation, crop variety, and indigenous methods of irrigation. The underlying principle among the farmers is that they employ farming methods available to them in their context to boost their productivity. A plethora of the methods that they employ are inherited from their forefathers and some are designed within the frontiers of their culture and environmental demands to meet their agricultural needs.

\section{IKS Strategies to promote entrepreneurship}

1. Crop rotation

Crop rotation is one of the methods that horticulture farmers in the district employ. The process has been practiced by many African communities over the years. The process boosts their productivity because the soil remains fertile for a longer time. Despite having Agricultural Extension (AGRITEX) advising farmers on farming practices such as crop rotation, the process was also found to have been passed from one generation to another and it emerged that communities used to receive guidance for such processes from their ancestors. One participant indicated that

...Crop rotation is one of the methods we employ to keep the land fertile. We have always been told by agriculture extension officers and other experts that we don't have to plant the same crops again and again on the same piece of

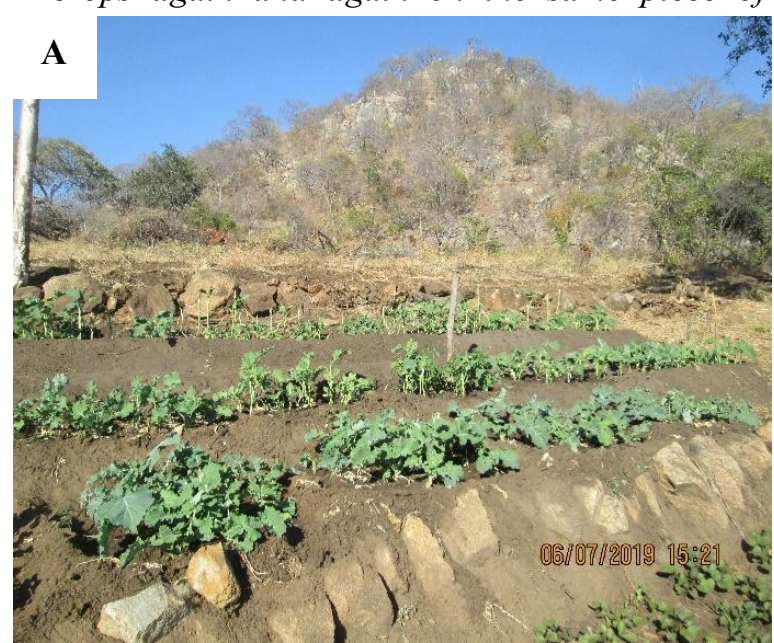

Figure 1. a) Vegetable Field; b) Tomato Field

Sources: Images taken by Shingirai Mugambiwa land. The method seems to be working but it's actually not new because we have always been practicing crop rotation and our forefathers did it at the instruction of the ancestors. So I can say it's more of an inherited method that has worked for us.

[Participant 2: In-depth interviews]

Several participants indicated that almost all of their crops require up to three months to ripen and that they will be seeding a fresh crop as soon as it is ready. Because they have irrigation, the method is viable. This means that they employ their irrigation options during seasons when precipitation is minimal. This is because the crop requires a lot of water, and if there aren't enough rains, there's a good probability of a bumper crop. Furthermore, some participants stated that one of their indigenous crop rotation practices that they inherited from their forefathers is that when the season is dry, the community would consult with the ancestors through a rain-making ceremony known as Mafuwe, following which they would receive abundant rain. Although the society no longer relies only on the dictates of the ancestors for agricultural decisions, some practices such as crop rotation are influenced by what was formerly known as the ancestor's role. Crop rotation as a purely indigenous agriculture-based method is supported by Kurukulasuriya and Mendelsohn (2006) who contend that crop rotation has always been part of the African farming culture. It emerged that the process was usually practiced in times when there were insufficient rains.

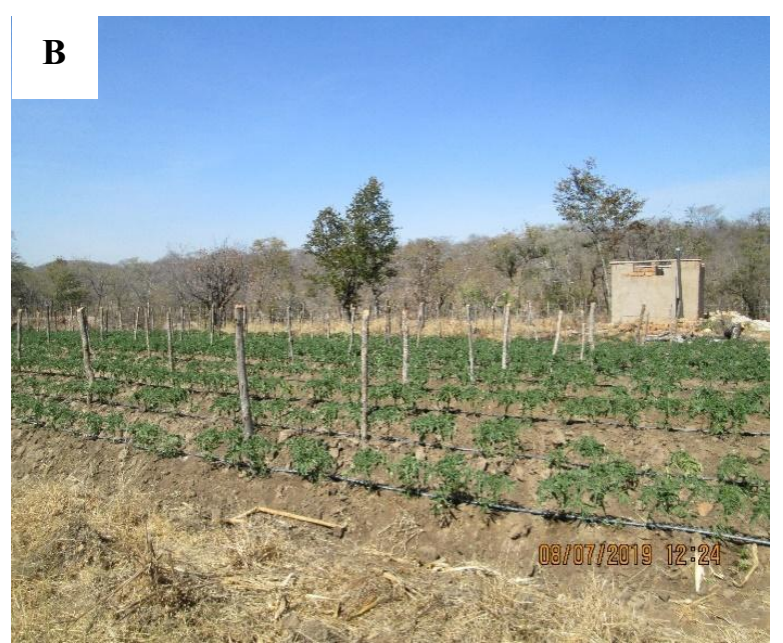




\section{Crop variety}

Crop variety is another method purported to be indigenous knowledge-based. It has emerged that one of the ways employed by horticulture farmers in Mutoko district is growing a variety of crops such as tomatoes, green vegetables, onions, butternut, etc at the same time. This method differs from the one in the previous section which is aimed at soil fertility. Figure 1 shows tomatoes and vegetable fields grown concurrently in Matedza village. Growing a variety of crops at the same time is a method developed by the community to minimize their chances of losses. The most dominant crops in the district are tomatoes and onions. The major reason for the two crops is that onion does not require a lot of water whereas it has a good market and does not easily go bad. Tomatoes are preferred because they are often in high demand on the market. It has also been revealed that tomatoes and onions have an all-year-round market and what might differ is the market price not the demand of the product. Moreover, the farmer indicated that after harvesting the crop is sold at MbareMusika (A marketplace located South of Harare the capital city of Zimbabwe).

...Our major crops include butternut, tomatoes, onions, and green vegetables. These crops are usually grown concurrently to minimize our chances of losses at the marketplace. In as much as demand is usually consistent for crops like tomatoes and onions, the selling prose usually differs. As such, when we have a variety chances of running a loss are minimum because the selling price or demand cannot be low for all the produce.

[Participant 4: In-depth interviews]

The narratives by the farmers revealed that horticulture is an entrepreneurial activity on which their families and overall livelihoods depend on. It has also emerged that to boost their productivity, the farmers employ numerous indigenous methods such as indigenous-based crop variety and crop rotation.

\section{IKS forms of irrigation}

Irrigation is a common practice among farmers around the world. Due to insufficient rains as a result of climate change, horticulture farmers in Mutoko district have developed irrigation methods peculiar to their context to boost their productivity. Many forms of irrigation have emerged in the area. The most economic and indigenous methods are the utilization of river waterholes, drilling wells on the riverside, and constructing their gardens in the vicinity of the rivers (See. Figure 1). The benefits of having wells close to the river are that water deposits are closer and the good mains high water levels for a long time. This practice is said to have been passed from one generation to another as indicated by one of the participants.

... Our main source of irrigation is rivers which dry prematurely. Nevertheless, our indigenous agricultural system has taught us that when the rains go prematurely, we use water from riverside wells to irrigate our plants. The system sustained our forefathers, and it has been passed from one generation to the other.

[Participant 5: In-depth interviews]

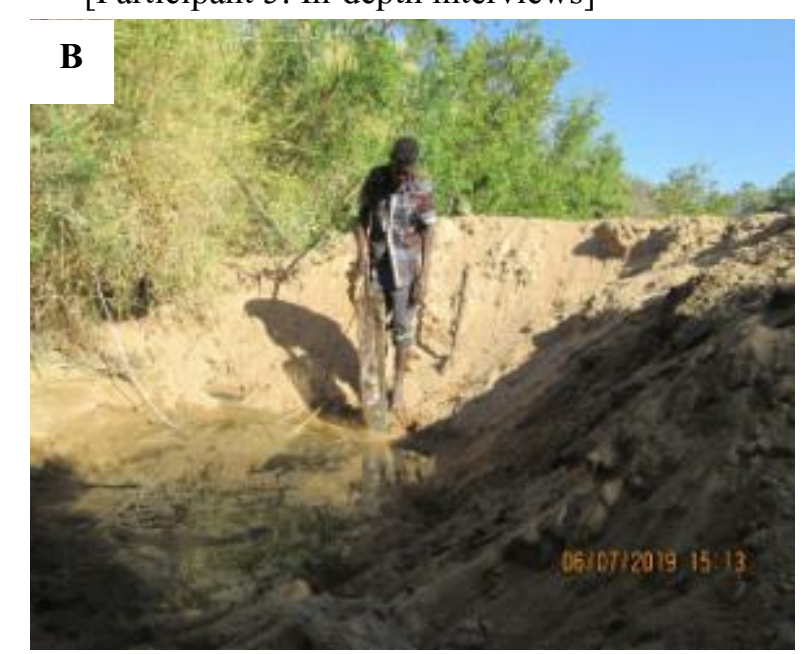

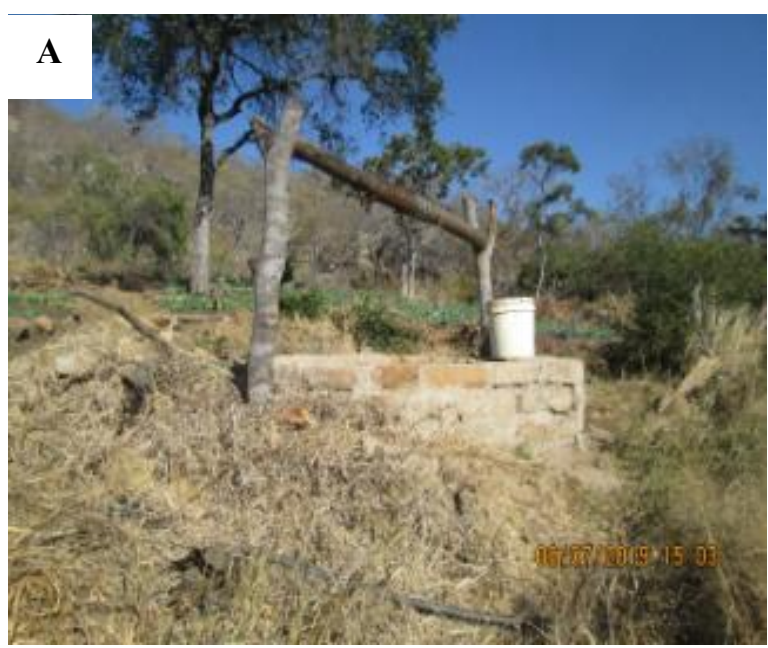

Figure 2: a) A hand-dug well on the riverside in Matedza village; b) river waterhole in Matedza village Source: Images taken by ShingiraiMugambiwa 
The use of river waterholes has become prevalent in the district and it is often complemented with hand-dug riverside wells as articulated by one of the participants.

...The early drying of the local rivers has prompted users to use silverside wells and river waterholes simultaneously as a method of irrigation. These are methods developed by the community and we have inspired one another to use this system of irrigation.

[Participant 8: In-depth interviews]

The widely dominant in Mutoko district is such that all farmers either use hand-dug wells or river waterholes or both. The widespread of the method has been necessitated by social networks wherein farmers share methods of agriculture. Mugambiwa (2020) emphasized the importance of sharing skills among farmers as a booster of productivity. Social networks have informed the prevalence of the methods of irrigation and that has helped a plethora of farmers to increase productivity and boost their profits. Elfring (2000) considers the environment and social networks as a significant component of entrepreneurship. Correspondingly, Bosma et al. (2000) contend that social capital is an important determinant of entrepreneurship. This implies that engaging other entrepreneurs in the same trade are one of the elements of this social capital. De Lauwere (2004) provided characteristics of a good entrepreneur some of which I found significant in this study. These characteristics closely depict the IKS entrepreneurial strategy practiced by horticulture farmers in this study. The characteristics proposed by De Lauwereare as follows; strategic planning, soil fauna, Relationship with relevant stakeholders, Craftsmanship, Networking, and Personal Characteristics. Nevertheless, for this study, strategic planning, relationship with relevant stakeholders, craftsmanship, and networking were found sufficing in the IKS narrative.

\section{Strategic Planning}

Strategic planning enables entrepreneurs to effectively establish their objectives. The process of strategic planning allows the farmer to acquire information that improves market perspectives and agricultural processes. As indicated in this study, farmers communicated with the social and commercial environment directly and indirectly linked to their agricultural process. Indigenous practices of social networking have assisted local farmers to acquire certain irrigation methods and farming practices most of which are borrowed from the previous generation. All this was in quest of increased production in pursuit of profit.

\section{Relationship with relevant stakeholders}

The findings of this study revealed that horticulture farmers have developed a relationship with other stakeholders such as buyers at the marketplace and agricultural extension officers. The kind of relationship established was purely informed by participants' responses to the demands of their immediate environment. De Lauwere (2004) contends that a good entrepreneur knows the significance of a good relationship with stakeholders. The success of horticulture farmers in Mutoko was brought about by their positive association with buyers at the marketplace such as Mbare Musika located south of Zimbabwe's capital city, Harare. One participant indicated that as farmers they do not dictate prices, rather they negotiate with the buyers and meet each other halfway.

6. Craftsmanship

The findings of this study established that farmers have a high level of production and product quality. This is significantly supported by their active role in ensuring optimal crop growth, prevention of pests, weeds, and diseases through indigenous-based methods. One farmer in the study has stressed the need for crop rotation to keep the soil fertile and he has successfully practiced the method for years.

\section{Networking}

The findings of this study have established that social networking is fundamental in horticulture entrepreneurship. De Lauwere (2004) insists that a good entrepreneur searches for decision-supporting information in an active and structured way. The author further argues that the network of a farmer should consist of other farmers, advisors, and sales representatives of various suppliers. In this study, the farmers have successfully formed social networks that they use to share knowledge and methods of farming practices such as irrigation modes as revealed by farmers in Matedza village. 


\section{CONCLUSION}

Horticulture farmers in this study have employed IKS in various ways related to their daily farming activities. Their entrepreneurship acumen has manifested from the preparation of what to grow to the selling of the product at the marketplace. The farmers have in many ways demonstrated characteristics of a good entrepreneur as stipulated by a notable entrepreneurship scholar De Lauwere. Nevertheless, it is important to note that these characteristics have been merged with IKS. The entrepreneurial strategies employed by farmers in this study demonstrated the significance of entrepreneurship in eradicating poverty and providing sustainable livelihoods for communities. The study established that IKS entrepreneurial strategies employed by Mutoko horticulture farmers are closely linked to western strategies. To put this into perspective, I merged De Lauwere's characteristics of a good entrepreneur with IKS characteristics of a good entrepreneur. The significance of embracing IKS in entrepreneurship among horticulture farmers essentially towards sustainable development. The study recommends the adoption of both IKS and conventional entrepreneurship to achieve the most anticipated sustainable development objectives.

\section{REFERENCES}

Bhatasara, S. (2015). Understanding Climate Variability and Livelihoods Adaptation in Rural Zimbabwe: A case of Charewa, Mutoko. PhD Thesis. Rhodes University.

Braun, V. \& Clarke, V. (2006). Using thematic analysis in psychology. Qualitative Research in Psychology, 3 (1), 77-101.

Chikosi, S., Mugambiwa, S.S., Tirivangasi, H.M \& Rankoana, S.A. (2018). Climate change and variability perceptions in Ga-Dikgale community in Limpopo Province, South Africa. International Journal of Climate Change Strategies and Management. 3 (1) 115.

Gandure, S., Walker, S. and Botha, J.J. (2013). Farmers'perceptions of adaptation to climate change and water stress in a South African rural community. Environ Dev. 5 (1), 39-53.

Kuchi VS, Salma Z. \& Kabir J. (2017). HortiTourism: A Value Added Approach for Economically Strengthening Farmers,
International Journal of Pure Applied Bioscience. 5 (3), 793-795.

Kurukulasuriya, P. \& Mendelsohn. R. (2006). Crop Selection: Adapting to Climate Change in Africa. CEEPA Discussion Paper Number 26, Centre for Environmental Economics and Policy in Africa, University of Pretoria.

Moyo, A. (2016). Dry times in Mutoko district.The Sunday Mail. 6 March 2016. Available at: http://www.sundaymail.co.zw/. (Accessed 09 July 2021).

Mugambiwa, S. S. \& Rukema, J. R. (2019). Rethinking indigenous climate governance through climate change and variability discourse by a Zimbabwean rural community. International Journal of Climate Change Strategies and Management. 3 (1)114.

Mugambiwa, S.S. (2018). Adaptation measures to sustain indigenous practices and the use of indigenous knowledge systems to adapt to climate change in Mutoko rural district of Zimbabwe. Jàmbá: Journal of Disaster Risk Studies. 10 (1), a388.

Mvumi, B., Donaldson, T. \& Mhunduru, J. (1988). A Report on Baseline Data Available For Mutoko District, Mashonaland East Province. University of Zimbabwe. Harare.

Senanayake, S. G. J. N. (2006). Indigenous knowledge as a key to sustainable development. Journal of Agricultural Sciences. 2 (1), 87-94.

Shields, P. \& Rangarjan, N. (2013). A Playbook for Research Methods: Integrating Conceptual Frameworks and Project management. Stillwater, OK: New Forums Press.

Sidhu, K. \& Kaur, S. (2006). Development of entrepreneurship among rural women. Journal of Social Science., 13(2): 147-149. 